Case Report

\section{A rare case report on pediatric shellfish allergy}

\author{
Ananta Jois ${ }^{1}$ and Betsy Mathew ${ }^{2 *}$
}

${ }^{1}$ Assistant Physician, Pediatric Intensive Care Unit, GG Hospital, Trivandrum, Kerala, India

${ }^{2}$ Consultant, Pediatric Intensivist, GG Hospital, Trivandrum, Kerala, India

\section{Introduction}

Shellfish are extensively consumed worldwide because of their nutritional value. In general they are good sources of low-fat protein rich in several essential vitamins and minerals as well as in the essential nutrients omega-3 long-chain polyunsaturated fatty acids (n-3 LCPUFAs) [1]. Shellfish belongs to "The Big 8" food groups causing allergy, which often does not outgrow during childhood. However, increase in IgE - mediated sea food allergy has been linked to shellfish. Seafood- associated shellfish include crustaceans \& molluskans [2]. These may cause mild local symptoms \& lead to severe systemic anaphylactic reactions by ingestion, inhalation, or contact. Globally, the prevalence of shellfish allergy estimated to be $0.5 \%$ to $2.5 \%$ of the general population [3]. There are limited data showing the prevalence of shellfish allergy in children.

A study on US pediatric population showed $1.3 \%$ of shellfish allergy. Children were more allergic to crustacean $(1.2 \%)$ than mollusks $(0.5 \%)$ [4]. Tropomyosin is the major allergen.

\section{Case description}

6-year old male child, native of Singapore was admitted to the pediatric intensive care unit of a tertiary hospital with alleged history of consumption of cooked crab meat followed by both eyelid swelling. Swelling was painful, itchy \& progressively increasing such that his vision was getting affected. He had no gastrointestinal (diarrhoea, vomiting, abdominal pain) symptoms/respiratory (breathing difficulty, cough) symptoms. On examination, tachycardia \& hypotension present. Systemic examination was normal (Figure 1).

No past history of any allergies/comorbidities like bronchial asthma.

He was treated with intravenous fluids, intravenous anti-histamine \& intramuscular epinephrine. Baseline blood investigations were normal \& total serum IgE level was high

\section{More Information}

*Address for Correspondence:

Dr. Betsy Mathew, Consultant, Pediatric Intensivist, GG Hospital, Trivandrum, Kerala, India, Tel: 8281736759

Email: betsymathew001@gmail.com

Submitted: 07 November 2020

Approved: 20 November 2020

Published: 23 November 2020

How to cite this article: Jois A, Mathew B. A rare case report on pediatric shellfish allergy. J Adv Pediatr Child Health. 2020; 3: 056-057.

DOI: 10.29328/journal.japch.1001018

Copyright: (c) 2020 Jois A, et al. This is an open access article distributed under the Creative Commons Attribution License, which permits unrestricted use, distribution, and reproduction in any medium, provided the original work is properly cited.

Check for updates OPEN ACCESS
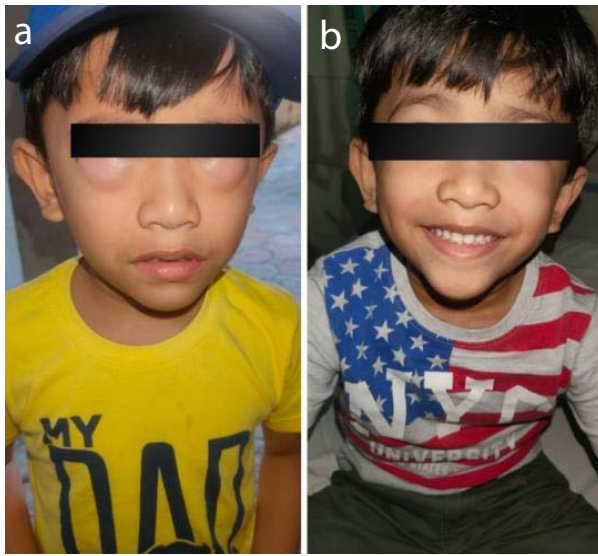

Figure 1: a): At admission. b): At dlscharge.

for age (200). Skin prick test denied by the parents \& Oral food challenge unattempted in view of its risks. Avoidance of the offending food was counselled to parents \& child was safely discharged in 24 hours.

\section{Discussion}

Shellfish and seafood are used synonymously among the general population. "Seafood" refers to those edible aquatic animals and "shellfish" refers to those with a shell or shelllike exoskeleton. Shellfish is furthur divided into two groups - crustacea and mollusks.

Shellfish toxic syndromes (shellfish poisoning) and Shellfish allergy are the broad conditions associated with 
shellfish consumption. Shellfish toxic syndromes include a wide variety of symptoms based on the amount of shellfish consumed and the concentration of toxins. This includes paralytic shellfish poisoning, neurotoxic shellfish poisoning, amnesic shellfish poisoning, diarrhetic shellfish poisoning, azaspiracids shellfish poisoning. All these poisonings maybe underdiagnosed when mild or misdiagnosed as allergy. Presence of similar symptoms in other individuals who shared the meal, absence of prior reactions to same shellfish meal \& its subsequent tolerance without symptoms should favour toxicity.

Many allergens have been identified in shellfish tropomyosin (main), arginine kinase, myosin light chain, sarcoplasmic binding protein. Among them, tropomyosin is the main crustacean allergen [5]. Symptoms due to allergic reaction from shellfish allergy range from mild to severe anaphylactic shock. True sensitization to shellfish specific allergens can be hampered due to the highly cross-reactive nature of some allergenic proteins. Tropomyosin has mainly linear IgE epitopes \& is important in determining the degree of cross-reactivity among shellfish species. Therefore, skin prick testing helps to detect clinically allergic patients. Serum based IgE (total and allergen-specific) quantifications are to be assessed. However, no species specific allergen has been identified so far to diagnose allergy to a specific crustacean/ molluskan species with the use of allergen molecules. Lastly, food challenge or double blind placebo controlled food challenge (DBPCFC) can be used to confirm clinical reactivity to crustacean \& mollusk species. In view of its high risks and cost, the food challenge is not done routinely.

\section{Conclusion}

Shellfish allergy being a rare entity in childhood needs a more wholesome approach in diagnosis and treatment aspects.

\section{Key message}

1) No cure for shellfish allergy.

2) Avoidance of shellfish is an ideal way to prevent it.

3) Epinephrine autoinjector may be advised to parents in the event of accidental ingestion of shellfish.

\section{References}

1. Bernstein AS, Oken E, de Ferranti S. Council on Environmental Health; Committee on Nutrition. Fish, Shellfish, and Children's Health: An Assessment of Benefits, Risks, and Sustainability. Pediatrics. 2019; 143: e20190999.

PubMed: https://pubmed.ncbi.nlm.nih.gov/31110165/

2. Khora S. Seafood-Associated Shellfish Allergy: A Comprehensive Review. Immunological Investigations. 2016; 45: 504-530. PubMed: https://pubmed.ncbi.nIm.nih.gov/27404324/

3. Woo C, Bahna S. Not all shellfish "allergy" is allergy!. Clinical and Translational Allergy. 2001.

4. Wang H, Warren C, Gupta R, Davis C. Prevalence and Characteristics of Shellfish Allergy in the Pediatric Population of the United States. J Allergy Clin Immunol Pract. 2020; 8: 1359-1370e2.

PubMed: https://pubmed.ncbi.nlm.nih.gov/31917365/

5. Lopata A, O'Hehir R, Lehrer S. Shellfish allergy. Clinical \& Experimental Allergy. 2010; 40: 850-858.

PubMed: https://pubmed.ncbi.nlm.nih.gov/20412131/ 